\title{
Does the presence of non-refluxing hydroureter impact the management and outcome of high-grade hydronephrosis?
}

Amr Hodhod $^{1,2}$; John-Paul Capolicchio ${ }^{1}$; Roman Jednak ${ }^{\mathbf{1}}$; Sunny Wei ${ }^{1}$; Mohamed Marzouk Abdallah $^{2}$; Abd El-Alim El-Doray ${ }^{2}$; Mohamed El-Sherbiny ${ }^{1}$

${ }^{1}$ Departments Pediatric Surgery, Montreal Children's Hospital, McGill University, Montreal, QC, Canada; ${ }^{2}$ Department of Urology, Faculty of Medicine, Menoufia University, Al Minufya, Egypt

Cite as: Can Urol Assoc J 2019 September 27; Epub ahead of print. http://dx.doi.org/10.5489/cuaj.6080

Published online September 27, 2019

$* * *$

\section{Abstract}

Introduction: We aimed to evaluate the impact of non-refluxing hydroureter on the initial management of high-grade hydronephrosis (HGH) management. Moreover, we evaluated the occurrence of febrile urinary tract infection (FUTI) and surgical intervention for conservatively managed units.

Methods: Patients' charts with postnatal hydronephrosis from 2008-2014 were retrospectively reviewed. We included patients who presented in the first year of life. All included patients had HGH (Society of Fetal Ultrasound [SFU] grades3 and 4) and all were non-refluxing using voiding cystourethrogram (VCUG). We categorized renal units into two groups: with hydroureteronephrosis (HUN) and without hydroureter (isolated hydronephrosis [IH]). We recorded the initial management. We evaluated the impact of non-refluxing hydroureter on hydronephrosis fate, FUTI, and change to surgery for those managed conservatively. Results: We included 169 patients (180 units). IH was diagnosed in 146 units (137patients), whereas 34 units (32 patients) had HUN. Median followup was 42.9 months. A total of 25.3\% of IH units (37/146) had initial surgical management in comparison to 5.1\% (2/34) of HUN units $(p=0.01)$. During conservative management, nine HUN patients $(30 \%)$ and $11 \mathrm{IH}$ patients $(10.7 \%)$ experienced FUTI ( $\mathrm{p}=0.009)$. Surgical intervention after failed conservative management was indicated for $12 \mathrm{IH}$ units (11\%) and six HUN units (18.8\%) $(\mathrm{p}=0.25)$. Anteroposterior diameter (APD) worsening was significantly associated with the change to surgery in IH group ( $\mathrm{p}=0.003)$. More than half (52.3\%) of IH units resolved during conservative management in comparison to $18.7 \%$ of HUN $(\mathrm{p}<0.001)$. HUN had longer time till resolution (log rank=0.004).

Conclusions: IH units had more initial surgical interventions. The FUTI rate was much higher in association with dilated ureter even under antibiotic coverage. HUN was associated with less and slower resolution rate. 


\section{Introduction}

Traditionally, the management of non-refluxing high-grade hydronephrosis (HGH), either isolated hydronephrosis (IH) or due to primary hydroureteronephrosis (HUN), was surgical. Yet more recent studies have shown that there is a potential for spontaneous resolution for non-refluxing $\mathrm{HGH}$. As such, there is a move toward non-surgical management whenever possible, with surgical management being reserved for the failure of initial conservative management. ${ }^{1-4}$

Though SFU grade 3-4 hydronephrosis has traditionally been considered to be the risk group and more inclined to early surgical and medical management ${ }^{5}$. In the current study, we present a our approach to the postnatal management of non-refluxing HGH. In this study, our aim was to evaluate the impact of dilated ureter on the management of HGH. Moreover, we aimed to evaluate the impact of dilated ureter on the fate of hydronephrosis and the occurrence of febrile urinary tract infection (FUTI) during conservative management. Our hypothesis was that the presence of hydroureter could increase the FUTI rate and could affect the resolution rate while managed conservatively but would have less initial surgical interventions in comparison to IH.

\section{Methods}

The study was conducted retrospectively in a single tertiary center. Following a search through medical records, we reviewed patients' charts who presented, to our urology clinic, with postnatal hydronephrosis during their first year of life, in the period between January 2008 and August 2014. We included patients who had HGH (SFU Grades 3-4). Patients with non-functioning kidneys, vesicoureteric reflux(VUR) and those with $<2$ years of follow-up were excluded. Patient demographics, laterality, and hydronephrosis grade were recorded. All data pertaining to serial ultrasounds, VCUG and Mercaptoacetyltriglycine (MAG-3) renal scan were reviewed. Further, all data related to the FUTI occurrence, continuous antibiotic prophylaxis(CAP), circumcision status and hydronephrosis outcome were recorded and analyzed.

SFU grade 3 was defined as renal pelvic dilation associated with dilation of all calyces. SFU grade 4 was defined as SFU grade 3 with the addition of notable parenchymal thinning. Depending on dilated ureter diameter, we defined hydroureter as distal ureteral diameter $\geq 7 \mathrm{~mm} .{ }^{4}$ To measure the ureteral diameter, ultrasound studies that were done in the $1^{\text {st }}$ year of life were all reviewed to be sure of the status of hydroureter. The ureteral diameter was measured in the transverse plane, posterior to the bladder; then, the greatest diameter, in all first-year ultrasounds, was recorded. Ureteral diameter was measured while the bladder was full.

VUR was initially assessed in all patients using cyclic VCUG. The presence of VUR was examined during both filling and voiding phases and patients with reflux were excluded.

FUTI was defined as body temperature $>39^{\circ} \mathrm{C}$ associated with pyuria and positive urine culture with a single pathogen at $>50000 \mathrm{CFU} / \mathrm{ml}$. The FUTI occurrence was extracted from patient's charts and microbiology reports.

Initial renogram was indicated for all patients with grade 4 hydronephrosis or at surgeon's discretion. Renogram findngs were reviewed by one urologist (A.H). Regarding the HUN group, the region of interest was drawn around the kidney, dilated pelvicalyceal system and dilated ureter. Renogram curve types were obstructive or non-obstructive. Obstructive curve was considered 
when continuously rising or slow down sloping without adequate washout $(<50 \%)$ in response to furosemide. non-obstructive renogram was defined as $\mathrm{T}_{1 / 2}<10$ minutes with complete tracer washout. Otherwise, the renogram was considered equivocal.

In our approach, the initial management line, either conservative or surgical, depended on the presence of indications for surgical management. Initial surgical management was indicated if DRF was $<40 \%$ and, at the same time, $\mathrm{T}^{1} \frac{1}{2}$ was $>20 \mathrm{~min}$. Moreover, other indications included patients with grade 4 single functioning kidney or bilateral grade 4 hydronephrosis.

Conservative management depended, primarily, on serial ultrasound scans and couseling regarding FUTI and constipation prevention. FUTI counseling included recognition teaching and proper genital hygiene. Moreover, older children were counseled on regular bowel and bladder habits to prevent constipation. The timeline of conservative management protocol is illustrated in Figure 1. CAP was indicated for SFU grade 4 cases and for patients experienced a second FUTI episode. We discontinued CAP if HGH was downgraded to low-grade hydronephrosis or the patient was toilet trained. Follow-up renograms, beyond the initial one, were indicated in cases of upgrading of SFU-grade 3 or stable SFU-grade 4.

We considered a failed conservative management with required surgical intervention if one of the following findings were observed: (a) upgrading hydronephrosis on two subsequent ultrasounds; (b) renal scintigraphy findings of decreased DRF $>10 \%$ and worsening drainage in association with worsening of hydronephrosis (by U/S). Moreover, recurrent FUTI ( $>2$ times) was considered an indication for surgery. If a patient experienced his first FUTI but under CAP (breakthrough FUTI), we would discuss with the family either the change of antibiotic and performing male circumcision or offer surgical intervention. Whereas in the case of a second breakthrough FUTI, surgical intervention would be warranted.

The hydronephrosis outcome was reviewed concerning the hydronephrosis fate and surgical intervention. The outcome was categorized as resolved, persistent, downgraded or worsened. Resolved hydronephrosis was defined as a spontaneous disappearance of pelvicalyceal dilation and a ureter diameter $\leq 4 \mathrm{~mm}$ if hydroureter was initially present. We considered a $\leq 4 \mathrm{~mm}$ ureteral diameter as reported by others as a normal finding in children. ${ }^{6,7}$ Worsening hydronephrosis was defined as upgrading of hydronephrosis, DRF worsening $>10 \%$ and presence of obstructive pattern on follow up renogram.

Our primary outcome was to evaluate the effect of the non-refluxing hydroureter on the management of HGH. Our secondary outcomes were to evaluate the conservative management in terms of the fate of hydronephrosis, FUTI and the need for surgery in relation to the presence of non-refluxing hydroureter.

The Statistical Package for the Social Sciences (SPSS ${ }^{\circledR}$, version20; SPSS Inc., IBM Corp., Armonk, NY, USA) was used to record patient data and for statistical analysis. Chi-squared test was used for analysis of categorical data while the Mann-Whitney U test was used for continuous data. We used Kaplan-Meier survival plot to evaluate the hydronephrosis resolution, regarding the presence of hydroureter. A p value of $<0.05$ was considered significant. 


\section{Results}

Of total reviewed 543 patients, 223 patients (236units) were diagnosed with HGH. Forty-two VUR units (40 patients) and 6 non-functioning renal units (6 patients) were excluded. Of the remaining patients, we excluded non-resolved 8 units (8 patients) with follow-up $<2$ years.

Total eligible cases were 169 patients (180units). IH was diagnosed in 146 units (137 patients), whereas 34 units had HUN (32 patients). Patients' demographics are demonstrated in table 1. Patients presented at a median age of 0.5 months (0.03-11.7). The median follow-up period was 43.7 months (11-108.7).

\section{Initial line of management (Figure 2)}

Twenty-five percent of IH units (37/146) underwent initial surgical intervention in comparison with $5.9 \%$ of HUN units (2/34). Notably, most HUN units were managed conservatively (94.1\%) while $75 \%$ of IH units were managed conservatively $(\mathrm{p}=0.01)$.

Both HUN units had initial surgical intervention at ages 1 and 7 months. Both underwent cutaneous ureterostomy then later on both had ureteral reimplantation at age 12 and 19.1 months respectively. All IH units that had initial surgical intervention underwent dismembered pyeloplasty at median age 3.5 months (1-18.1).

\section{Renal function}

IH units that underwent initial surgical interventions had median DRF of 43\% (12-100) with median $\mathrm{T}_{1 / 2} 26$ min (4.8-172). Three IH units underwent surgeries because of single functioning kidneys. Moreover, 3 patients with bilateral grade 4 hydronephrosis underwent surgical interventions. However, none of the 3 patients had obstuctive renograms with a median T1/2 of 12.6 minutes (4.8-22). Two HUN units were operated initially due to DRF < 40\% (15\% and 34\%). These HUN units had $\mathrm{T}_{1 / 2}$ of 4 minutes and 20.5 minutes.

For renal units that had initial conservative management, 25/30 (83.3\%) patients with HUN (28 units) and 63/103 (61.2\%) IH patients (67 units) underwent MAG-3 studies. Non-obstructive renogram was diagnosed in 24/28 HUN units (85.7\%) and 54/67 IH units (80.6.1\%) $(\mathrm{p}=0.55)$. Remaining IH units (10/68) had equivocal renogram studies or obstructive renogram (2/68). While remaining HUN were 3 equivocal renograms and one obstructive. Regarding renal units with obstructive renograms, the two IH units showed improvement on follow-up ultrasound scan while the HUN unit had surgical intervention at age 12.3 months. The median Post-Lasix $\mathrm{T}_{1 / 2}$ of the HUN group was 4.7 minutes(1-32) and 4.1 minutes(1-53) for the IH group(p=0.89).

\section{FUTI during conservative management (Table 2)}

FUTI was diagnosed in 30\% (9/30) of HUN patients in comparison to $10.7 \%(11 / 103)$ of IH patients $(\mathrm{p}=0.009)$. The median initial ureteral diameter of HUN units that developed FUTI was 10mm (7-11.7). Thirty-two percent of IH received CAP in comparison to 63.3\% of HUN group. The median duration of CAP was higher in the HUN group in comparison to IH patients (13 months vs. 6 months) ( $\mathrm{p}<0.001)$. Despite CAP, 33.3\% of HUN patients $(3 / 9)$ and one IH patient had breakthrough FUTI ( $\mathrm{p}=0.17)$. HUN and IH patients who did not receive CAP were followed for a median duration of 41.1 months (13-83.5) and 35.4 months (11-91) respectively. 
Notably, none of the circumcised patients has developed FUTI. Three circumcised HUN patients $(60 \%)$ and $6 / 26 \mathrm{IH}$ patients $(23.1 \%)$ had CAP $(\mathrm{p}=0.1)$. On the other hand, 4/15 uncircumcised patients with HUN (26.7\%) and 7/62 uncircumcised patients with IH (11.3\%) experienced FUTI ( $\mathrm{p}=0.13)$.

\section{Fate of hydronephrosis during conservative management (Table2)}

Sixty-three percent of HUN units and $78.9 \%$ of IH units were downgraded or resolved $(p=0.06)$. The median age at resolution was 38.7 months (6.3-81.3) (Table3). The median initial ureteral diameter for resolved HUN units was $7.2 \mathrm{~mm}$ (7 - 9.7). Most of patients with resolved hydronephrosis had $<5$ ultrasounds until documented resolution (66.7\% for HUN and 79.2\% for $\mathrm{IH})$. Before resolution, a follow-up renogram was needed for only $21 \%$ of IH patients while was needed for one HUN patient ( $\mathrm{p}=0.82$ ). In terms of survival analysis, the presence of hydroureter had decreased the resolution rates $(\mathrm{p}=0.004)$ (Figure 3$)$.

Worsening hydronephrosis was observed in 6/32 (18.7\%) HUN units and 12/109 IH units (11\%) ( $\mathrm{p}=0.5)$. Regarding the HUN group, 2 units (SFU 3) showed upgrading on follow-up ultrasound while 4 units (SFU 4) showed worsening hydronephrosis on renogram follow- up. Two of these SFU 4 units had DRF decline $>10 \%$ and the remaining 2 units had obstructive renogram. For IH group, no units had declined renal function during follow-up. Worsened grade $4 \mathrm{HI}$ units had obstructive follow-up renogram while SFU grade3 showed upgrading to grade4 with the presence of obstructive renogram.

\section{Subsequent surgical interventions (Failed conservative management)}

Nineteen percent of conservatively managed HUN units (6/32) and 11\% of IH units (12/109) underwent surgical interventions $(p=0.25)$. There was no difference in the median age at surgery between both groups $(\mathrm{p}=0.9)$. In the HUN group, the causes of surgical interventions were worsening hydronephrosis (4 units), recurrent FUTI (2 units). All of the IH were operated after conservative management due to worsening hydronephrosis.

The median last-APD before surgery of IH Units was $26.3 \mathrm{~mm}$ (15-40) in comparison to a median initial-APD of $11 \mathrm{~mm}(5.6-25)$ ( $\mathrm{p}=0.003)$. Similarly, the median preoperative APD (16mm) of HUN units was not significantly changed from the initial ones $(11 \mathrm{~mm})(p=0.17)$. On the other hand, the median ureteral diameter of HUN units before surgery was $13 \mathrm{~mm}$ (9.6-19) while the median initial diameter was $11 \mathrm{~mm}(8-16)(\mathrm{p}=0.34)$.

Preoperatively, we ordered a repeated renogram for all patients. For those with IH, 6 units (50\%) had obstructive renograms, equivocal in 2 units (16.7\%) while the remaining had nonobstructive curves. None of these IH units had an initial obstructive renogram. On the other side, 4 HUN units, that had worsening hydronephrosis and underwent surgical interventions, had obstructive curves when repeating renograms.

2/6 HUN units that underwent surgical intervention after conservative management had $>1$ procedure. Cutaneous ureterostomy was performed at ages 5 and 4.8 months. Later on, Ureteral reimplantation was done at ages 9.8 and 19.2months respectively. 


\section{Discussion}

With respect to the long-term management of AHN and the advent of conservative management of $\mathrm{HGH}$, the objectives have been to design an approach which avoids surgery, but preserves renal function and prevents FUTIs. With milder hydronephrosis grades, a purely conservative approach is broadly accepted. ${ }^{8,9}$ With higher hydronephrosis grades, the trend in the available literature indicates that there is a strong correlation between severe pathology and surgical intervention, and similarly between hydronephrosis worsening and increasing FUTI risk. ${ }^{10}$ The current practice regarding the management of non-refluxing HGH varies significantly, on an institutional, national and international basis.

Some may raise the point that we compared two different diagnoses. However, our aim was to evaluate the impact of dilated ureter on the HGH management. As the management protocol is usually the same for all HGH units. In order to study that impact, we divided all nonrefluxing HGH units into 2 main categories: those with dilated ureter "HUN group" and the remaining units with HGH were categorized as “IH group”. In their study, Braga et al compared the FUTI incidence between units with dilated ureter (32\%) and those without dilated ureters $(6 \%)^{11}$

In our study, we focused on patients with non-refluxing HGH, given that VUR is a known risk factor for FUTI and disease progression, and consequently, well discussed in previous studies. $^{12,13}$

In Coelho et al., 51\% of IH units with moderate to high hydronephrosis underwent pyeloplasty during 2years follow-up . ${ }^{14}$ In our study only $25.3 \%$ of IH had initial surgical management. This difference may be related to different indications of surgery and our preference for a trial of conservative management. Braga et al. had a $28.8 \%$ of HGH with HUN underwent surgical interventions which was similar to 23.5\% (8/34) of our HUN units (2 units initially and 6 units after failed conservative management). ${ }^{15}$ Despite there was no difference in the percentage of units that had surgical interventions. We noted that $50 \%$ of HUN units that had surgical interventions (4/8) had $>1$ procedure while all of $\mathrm{IH}$ underwent one procedure. This reflects the complexity of surgical intervention in this group of patients.

Some studies have shown that there is potential for IH cases to resolve spontaneously over time and there has been an attempt to stratify patients based on their likelihoods for resolution. ${ }^{1}$ Ulman et al. published a prospective study of 104 infants with unilateral non-refluxing IH. In their cohort, $22 \%$ of patients underwent pyeloplasty, $54 \%$ had resolution to grade 0 or 1 and $24 \%$ had improvement to grade 2 or 3 at 5 years, with a mean time to complete resolution of 19 months. ${ }^{16}$ The current study produced similar results, with complete resolution in $52.3 \%$ of $\mathrm{IH}$ units, downgrading in $26.6 \%$, non-changed in $10.1 \%$ and surgical management in $11 \%$ at a median follow-up of 42.4 months, with a median age at resolution of 31.8 months. The differences in time to resolution and the percentage of cohort with complete resolution were likely due to our strict definition of resolution. It is interesting to note that even though $26.2 \%$ of our conservatively managed patients had bilateral hydronephrosis; only 11\% required further surgical management in comparison with $22 \%$ in Ulman et al study. This could be explained by that $63.1 \%$ of our IH 
patients with failed conservative management had either pre-operative obstructive or equivocal renograms in comparison to $91 \%$ of Ulman et al.’s surgical sub-cohort. ${ }^{16}$

In consideration of the HUN cohort, our results were consistent with the trends seen in the current literature that recommend initial conservative management for HUN in the absence of significant obstructive uropathy. ${ }^{4}$ During conservative management, $18.7 \%$ of our HUN units were resolved with a median time to complete resolution being 41.1 months. Nineteen percent of our HUN group required operative management after failed conservative management. Interestingly, HUN and IH units that underwent surgical intervention after failed conservative management had similar age at surgery (12.6 vs. 15.2 months respectively) $(\mathrm{p}=0.9)$. DiRenzo et al. found that, in patients with $\mathrm{HGH}$, there was resolution $12.2 \%$ of units in the first year of life. ${ }^{2}$ Despite the similarity in the resolution rate, our cohort had a longer time till resolution. That can be explained by the different definition of resolution between both studies.

In the current study, we found that IH units that underwent surgical interventions had significant worsening of APD while HUN units that had failed conservative management had no significant worsening for both APD or ureteral diameter. In our opinion, more prospective studies with larger number of patients would be needed to confirm the HUN findings.

In another study, 80 patients with primary HUN were prospectively followed for a mean time of 26.3 months, of which $82 \%$ had HGH. They found that, with respect to their entire cohort, $76 \%$ of patients experienced spontaneous resolution at a median follow-up of 19 months. ${ }^{15}$ The difference in the resolution rate is likely due to their resolution definition as an APD of $<10 \mathrm{~mm}$, $\mathrm{SFU}<2$, or ureter diameter $<8 \mathrm{~mm}$, while we required a ureteral diameter $\leq 4 \mathrm{~mm}$. This is compounded by the inclusion of both high and low-grade hydronephrosis, while our cohort consisted only of $\mathrm{HGH}^{15}$

An issue of particular controversy in the management of non-refluxing $\mathrm{HGH}$ is the use of CAP. Though the SFU consensus recommends CAP in cases of HGH, with or without hydroureter, it is not universally echoed in the field. ${ }^{10}$ In support of CAP, a systematic review suggested that there is value in offering CAP to infants with $\mathrm{HGH} .{ }^{17}$ This notion is supported by other groups, who have found that the UTI risk approaches $30-40 \%$ with non-refluxing HGH. ${ }^{18,19}$ Lee et al. identified HGH, hydroureter and obstructive uropathy as independent risk factors for FUTI, separate from the presence of reflux. ${ }^{19}$ This is consistent with the findings in our study, as FUTI was diagnosed in $30 \%$ of HUN patients, compared to $10.7 \%$ of $\mathrm{IH}$ patients who had conservative management ( $\mathrm{p}=0.009$ ). Further, during conservative management, HUN patients required a significantly longer duration of CAP than IH patients $(p=0.001)$. As supported by our previous results, the hydroureter itself increases the FUTI risk. ${ }^{20}$

To our knowledge, no comparative study evaluated the conservative management of HGH regarding the presence of dilated ureter. Collectively, we found that the associated hydroureter worsens the prognosis of HGH in terms of lower resolution rate, higher chance to change to surgery and more FUTI susceptibility. Dilated ureter negatively impacts complete resolution ( $p=0.004$ ) with longer median time till resolution. A possible explanation for this is that the natural history of HUN trends toward a slow disease improvement, especially when our resolution criteria 
were quite strict. This notion is supported by Arena et al., which suggests that the time of spontaneous resolution of a primary HUN may exceed 3.6years. ${ }^{21}$

The limitations of this study lie in being a retrospective review. Though a conservative approach was used throughout the study, individual practice preferences of different surgeons and patients lead to discrepancies in the prescription of antibiotics and change to surgical intervention. However, our indications for surgical intervention or CAP are similar to the BAPU and the SFU recommendations. ${ }^{4,10}$ In addition, a small number of patients with HUN was included in our study; however, it is comparable to the numbers of patients with high-grade HUN of other studies ${ }^{2,21}$. Indeed, prospective controlled studies are needed to truly examine CAP effectiveness and utility.

\section{Conclusions}

Renal units with IH had four times more initial surgical interventions than those with HUN. The rate of FUTI was almost triple in association with hydroureter even under antibiotics coverage. None of the circumcised patients experienced FUTI. The presence of dilated ureter decreased the resolution rate by almost $50 \%$. HUN was associated with a higher rate of failed conservative management and more complexity of surgical intervention. 


\section{Referances}

1. Liu DB, Armstrong WR, 3rd, Maizels M. Hydronephrosis: prenatal and postnatal evaluation and management. Clin Perinatol 2014; 41(3): 661-78.

2. DiRenzo D, Persico A, DiNicola M, et al. Conservative management of primary nonrefluxing megaureter during the first year of life: A longitudinal observational study. $J$ Pediatr Urol 2015; 11(4): 226 e1-6.

3. Oliveira EA, Oliveira MC, Mak RH. Evaluation and management of hydronephrosis in the neonate. Curr Opin Pediatr 2016; 28(2): 195-201.

4. Farrugia MK, Hitchcock R, Radford A, et al. British Association of Paediatric Urologists consensus statement on the management of the primary obstructive megaureter. $J$ Pediatr Urol 2014; 10(1): 26-33.

5. Fernbach SK, Maizels M, Conway JJ. Ultrasound grading of hydronephrosis: introduction to the system used by the Society for Fetal Urology. Pediatr Radiol 1993; 23(6): 478-80.

6. Hellstrom M, Hjalmas K, Jacobsson B, et al. Normal ureteral diameter in infancy and childhood. Acta Radiol Diagn (Stockh) 1985; 26(4): 433-9.

7. Cussen LJ. Dimensions of the normal ureter in infancy and childhood. Invest Urol 1967; 5(2): 164-78.

8. Mallik M, Watson AR. Antenatally detected urinary tract abnormalities: more detection but less action. Pediatr Nephrol 2008; 23(6): 897-904.

9. Davenport MT, Merguerian PA, Koyle M. Antenatally diagnosed hydronephrosis: current postnatal management. Pediatr Surg Int 2013; 29(3): 207-14.

10. Nguyen HT, Herndon CD, Cooper C, et al. The Society for Fetal Urology consensus statement on the evaluation and management of antenatal hydronephrosis. J Pediatr Urol 2010; 6(3): 212-31.

11. Braga LH, Farrokhyar F, D'Cruz J, et al. Risk factors for febrile urinary tract infection in children with prenatal hydronephrosis: a prospective study. J Urol 2015; 193(5 Suppl): 1766-71.

12. Burge DM, Griffiths MD, Malone PS, et al. Fetal vesicoureteral reflux: outcome following conservative postnatal management. J Urol 1992; 148(5 Pt 2): 1743-5.

13. Mathews R, Carpenter M, Chesney R, et al. Controversies in the management of vesicoureteral reflux: the rationale for the RIVUR study. J Pediatr Urol 2009; 5(5): 33641.

14. Coelho GM, Bouzada MC, Pereira AK, et al. Outcome of isolated antenatal hydronephrosis: a prospective cohort study. Pediatr Nephrol 2007; 22(10): 1727-34.

15. Braga LH, D'Cruz J, Rickard M, et al. The Fate of Primary Nonrefluxing Megaureter: A Prospective Outcome Analysis of the Rate of Urinary Tract Infections, Surgical Indications and Time to Resolution. J Urol 2016; 195(4 Pt 2): 1300-5.

16. Ulman I, Jayanthi VR, Koff SA. The long-term followup of newborns with severe unilateral hydronephrosis initially treated nonoperatively. J Urol 2000; 164(3 Pt 2): 11015.

17. Braga LH, Mijovic H, Farrokhyar F, et al. Antibiotic prophylaxis for urinary tract infections in antenatal hydronephrosis. Pediatrics 2013; 131(1): e251-61.

18. Coelho GM, Bouzada MC, Lemos GS, et al. Risk factors for urinary tract infection in children with prenatal renal pelvic dilatation. J Urol 2008; 179(1): 284-9.

19. Lee JH, Choi HS, Kim JK, et al. Nonrefluxing neonatal hydronephrosis and the risk of urinary tract infection. J Urol 2008; 179(4): 1524-8. 
20. Hodhod A, Capolicchio JP, Jednak R, et al. Evaluation of Urinary Tract Dilation Classification System for Grading Postnatal Hydronephrosis. J Urol 2016; 195(3): 725-30.

21. Arena S, Magno C, Montalto AS, et al. Long-term follow-up of neonatally diagnosed primary megaureter: rate and predictors of spontaneous resolution. Scand J Urol Nephrol 2012; 46(3): 201-7. 


\section{Figures and Tables}

Fig. 1. The timeline of conservative management of high-grade hydronephrosis. *Followup was ended if resolution was documented in two consecutive ultrasounds (U/S). VCUG: voiding cystourethrogram.

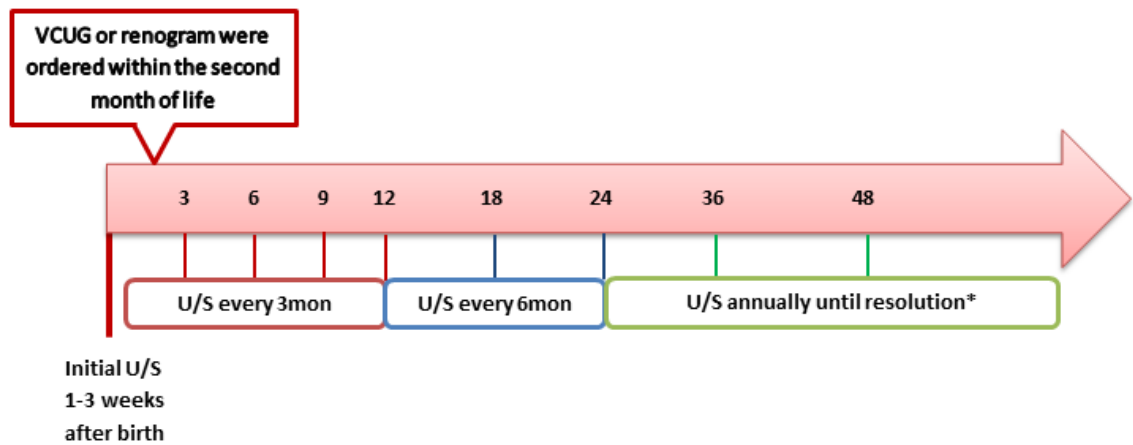

\begin{tabular}{|c|c|c|c|c|}
\hline & & $\begin{array}{c}\text { HUN } \\
\text { (32 patients, } 34 \\
\text { units) } \\
\end{array}$ & $\begin{array}{c}\text { IH } \\
\text { (137 patients, } 146 \\
\text { units) } \\
\end{array}$ & $\mathbf{p}$ \\
\hline \multicolumn{2}{|c|}{ Age at presentation median(range) } & $0.5(0.06-6.9)$ & $0.5(0.03-11.7)$ & $0.75^{*}$ \\
\hline \multirow{2}{*}{ Gender } & Male, n (\%) & $21(65.6)$ & $111(81)$ & \multirow{2}{*}{$0.06^{\wedge}$} \\
\hline & Female, n (\%) & $11(34.4)$ & $26(19)$ & \\
\hline \multirow[b]{2}{*}{ Laterality } & Unilateral, n (\%) & $22(68.8)$ & $102(74.5)$ & \multirow[b]{2}{*}{$0.51^{\wedge}$} \\
\hline & $\begin{array}{l}\text { Bilateral n(\%) } \\
\text { Bilateral HG/bilateral (HG +LG) }\end{array}$ & $\begin{array}{c}10(31.2) \\
2 / 8\end{array}$ & $\begin{array}{c}35(25.5) \\
9 / 26\end{array}$ & \\
\hline \multirow[t]{2}{*}{ Side } & Right, n (\%) & $12(35.3)$ & $35(24)$ & \multirow{2}{*}{$0.18^{\wedge}$} \\
\hline & Left, n (\%) & $22(64.7)$ & $111(76)$ & \\
\hline \multirow{2}{*}{ SFU } & Grade 3, n (\%) & $23(67.6)$ & $96(65.8)$ & \multirow{2}{*}{$0.83^{\wedge}$} \\
\hline & Grade 4, n (\%) & $11(32.4)$ & $50(34.2)$ & \\
\hline \multicolumn{2}{|c|}{ Ureteral diameter median (range) } & $9.1(7-17.5)$ & $0(0-6.6)$ & $<0.001^{*}$ \\
\hline \multicolumn{2}{|c|}{ Antibiotic prophylaxis, n (\%) } & $19 / 34(55.9)$ & 48/137 (33.6) & $<0.03^{\wedge}$ \\
\hline \multicolumn{2}{|c|}{ Circumcision status, n (\%) } & $6 / 21(28.6)$ & 33/111 (33.7) & $0.9^{\wedge}$ \\
\hline \multirow[b]{4}{*}{ Renograms } & Patients, n (\%) & 28/32 (87.5) & 95/137 (69.3) & $0.043^{\wedge}$ \\
\hline & DRF, median (range) & $50 \%(12-73)$ & $49 \%(12-100)$ & $0.96^{*}$ \\
\hline & T1², median (range) & $4.7 \min (1.1-115)$ & $9.3 \min (0-650)$ & $0.03^{*}$ \\
\hline & $\begin{array}{l}\text { Curve } \\
\text { Obstructive, n (\%) } \\
\text { Non-obstructive, n (\%) } \\
\text { Equivocal, n (\%) }\end{array}$ & $\begin{array}{c}2(6.9) \\
23(79.3) \\
4(13.8) \\
\end{array}$ & $\begin{array}{l}39(37.9) \\
54(52.4) \\
10(10.7) \\
\end{array}$ & $0.03^{\wedge}$ \\
\hline \multirow{2}{*}{$\begin{array}{l}\text { First-line } \\
\text { management }\end{array}$} & Conservative, n (\%) & $32(94.1)$ & $109(74.7)$ & \multirow{2}{*}{$0.01^{\wedge}$} \\
\hline & Surgical, n (\%) & $2(5.9)$ & $37(25.3)$ & \\
\hline
\end{tabular}

${ }^{\lambda}$ Chi square test was used for statistical analysis. ${ }^{*}$ Independent Samples Mann-Whitney U test was used for statistical analysis. DRF: differential renal function; HG: high-grade; HUN: hydroureteronephrosis; IH: isolated hydronephrosis; LG: low-grade. 


\begin{tabular}{|c|c|c|c|c|}
\hline \multicolumn{2}{|l|}{ 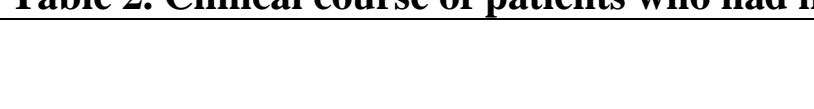 } & $\begin{array}{c}\text { HUN } \\
\text { (30 patients, } 32 \text { units) }\end{array}$ & $\begin{array}{c}\text { IH } \\
\text { (103 patients, } 109 \text { units) }\end{array}$ & $\mathbf{p}$ \\
\hline \multicolumn{2}{|c|}{ Followup period, median (range) } & $\begin{array}{l}57.2 \text { months } \\
(17.6-106.1)\end{array}$ & $\begin{array}{l}\text { 42.4 months } \\
(11-108.7)\end{array}$ & $0.17^{*}$ \\
\hline \multirow{2}{*}{ Gender } & Male, n (\%) & $20(66.7)$ & $88(85.4)$ & \multirow{2}{*}{0.02} \\
\hline & Female, n (\%) & $10(33.3)$ & $15(14.6)$ & \\
\hline \multirow[b]{2}{*}{ Laterality } & Unilateral, n (\%) & $19(63.3)$ & $76(73.8)$ & \multirow[b]{2}{*}{0.26} \\
\hline & $\begin{array}{l}\text { Bilateral, n (\%) } \\
\text { Bilateral HG/bilateral (HG } \\
\text { +LG) }\end{array}$ & $\begin{array}{c}11(36.7) \\
2 / 9\end{array}$ & $\begin{array}{c}27(26.2) \\
6 / 21\end{array}$ & \\
\hline \multirow{2}{*}{ SFU } & Grade 3, n (\%) & $23(71.9)$ & $90(82.6)$ & \multirow{2}{*}{0.18} \\
\hline & Grade 4, n (\%) & $9(28.1)$ & 19 (17.4) & \\
\hline \multirow{2}{*}{$\begin{array}{l}\text { A.B } \\
\text { prophylaxis }\end{array}$} & Patients, n (\%) & 19/30 (63.3) & $33 / 103(32)$ & $<0.001^{\wedge}$ \\
\hline & Duration median (range) & 13 months (3-48) & 6 months (3-24) & $0.001^{*}$ \\
\hline \multicolumn{2}{|c|}{ Circumcision, $\mathrm{n}(\%)$} & $5 / 20^{* *}(25)$ & $26 / 88^{* * *}(29.5)$ & 0.67 \\
\hline \multicolumn{2}{|c|}{$\begin{array}{l}\text { FUTI n(\%) } \\
\quad \text { Breakthrough FUTI, n (\%) } \\
\text { Recurrent FUTI, n (\%) }\end{array}$} & $\begin{array}{l}\text { 9/30 (30) } \\
3 / 9(33.3) \\
4 / 9(66.7)\end{array}$ & $\begin{array}{c}11 / 103(10.7) \\
1 / 11(9.1) \\
2 / 11(18.2)\end{array}$ & $\begin{array}{c}0.009^{\wedge} \\
0.17 \\
0.2\end{array}$ \\
\hline \multicolumn{2}{|c|}{$\begin{array}{l}\text { Fate of hydronephrosis } \\
\text { Resolved, } \mathrm{n}(\%) \\
\text { Downgraded, n (\%) } \\
\text { Worsening, n (\%) } \\
\text { Stable, n (\%) }\end{array}$} & $\begin{array}{l}6(18.7) \\
14(43.9) \\
6(18.7) \\
6(18.7)\end{array}$ & $\begin{array}{l}57(52.3) \\
29(26.6) \\
12(11) \\
11(10.1)\end{array}$ & $\begin{array}{c}<0.001^{\wedge} \\
0.06^{\wedge} \\
0.25^{\wedge} \\
0.19^{\wedge}\end{array}$ \\
\hline \multirow{2}{*}{$\begin{array}{l}\text { Failed } \\
\text { conservative } \\
\text { management }\end{array}$} & $\begin{array}{l}\text { Changed to surgery, n (\%) } \\
\text { Grade 3/4 }\end{array}$ & $\begin{array}{c}6 / 32(18.7) \\
2 / 4\end{array}$ & $\begin{array}{l}12 / 109(11) \\
6 / 6\end{array}$ & $\begin{array}{c}0.25^{\wedge} \\
0.5\end{array}$ \\
\hline & Age at surgery, median (range) & 12.6 months (5.1-56) & 15.2 months (7-36) & $0.9^{*}$ \\
\hline
\end{tabular}

${ }^{\wedge}$ Chi square test was used for statistical analysis. Independent Samples Mann-Whitney U test was used for statistical analysis. ${ }^{* *}$ The total number represents males. FUTI: febrile urinary tract infection; HG: high-grade; HUN: hydroureteronephrosis; IH: isolated hydronephrosis; LG: low-grade. 


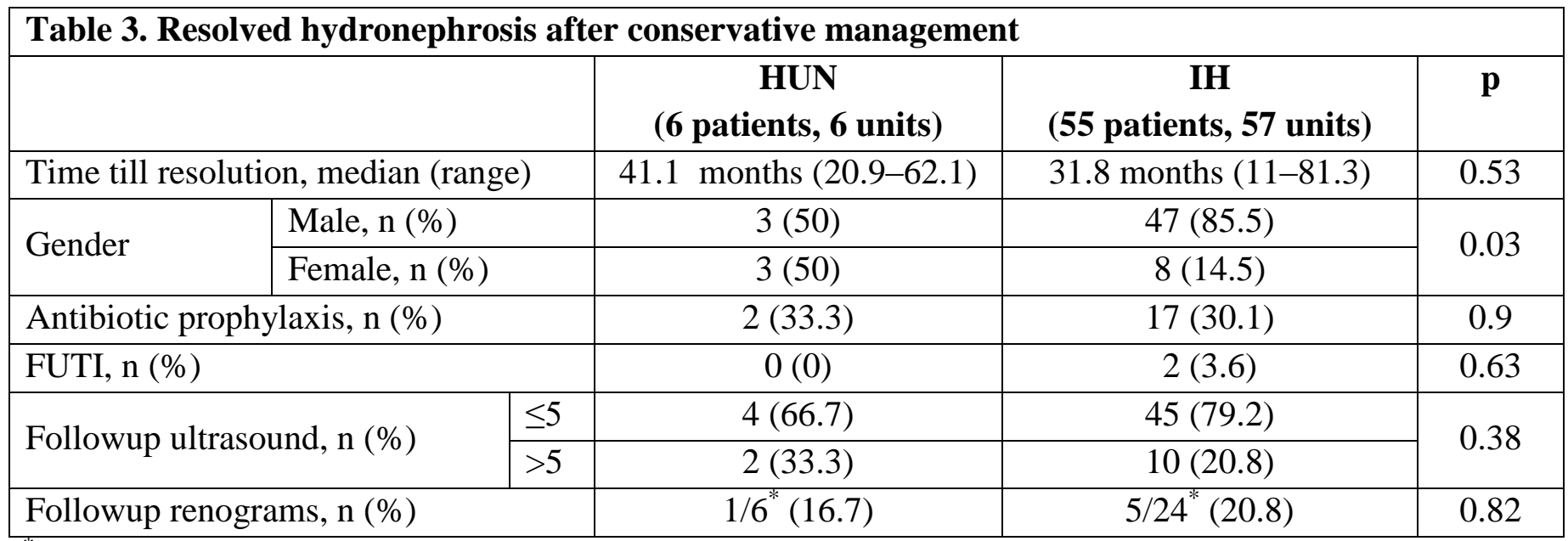

${ }^{*}$ Numbers are presented in relation to those had initial renograms. . FUTI: febrile urinary tract infection; HUN: hydroureteronephrosis; IH: isolated hydronephrosis. 